\title{
UVA and endogenous photosensitizers - the detection of singlet oxygen by its luminescence $\dagger$
}

\author{
Wolfgang Bäumler, Johannes Regensburger, Alena Knak, Ariane Felgenträger and Tim Maisch
}

Received 12th May 2011, Accepted 26th August 2011

DOI: 10.1039/c1pp05142c

UVA irradiation (320-400 nm) comprises about 95 percent of incident midday solar ultraviolet irradiation. It penetrates skin much deeper than UVB irradiation. The absorption of UVA irradiation in endogenous chromophores frequently leads to the generation of reactive oxygen species such as singlet oxygen $\left({ }^{1} \mathrm{O}_{2}\right) .{ }^{1} \mathrm{O}_{2}$ is an important biochemical intermediate in multiple biological processes. Beside other procedures, the direct detection of ${ }^{1} \mathrm{O}_{2}$ by its luminescence is a powerful tool that helps to understand the generation of ${ }^{1} \mathrm{O}_{2}$ during UVA exposure in solution, in vitro and in vivo. This article describes the endogenous photosensitizers, their ability to generate ${ }^{1} \mathrm{O}_{2}$ under UVA irradiation, and the detection technology to visualize the action of ${ }^{1} \mathrm{O}_{2}$.

\section{Introduction}

Solar UV radiation causes many adverse effects in tissue such as skin, which can be attributed to DNA damage. Consequently, skin cancer has accounted for about 40 percent of all cancers in the United States and their frequency has been increasing. ${ }^{1} \mathrm{UVB}$ $(280-320 \mathrm{~nm})$ is directly absorbed by cellular DNA, resulting in dipyrimidine lesions that include cyclobutane pyrimidine dimers (CPD), especially thymine dimers or pyrimidine photoproducts. ${ }^{2}$

The major component of solar radiation $(\sim 95 \%)$ is UVA $(320$ $400 \mathrm{~nm}$ ), which has been shown to produce likewise deleterious biological effects. ${ }^{3}$ Exposure to UVA irradiation has been recognized as a source of aging of eye lens proteins and as a risk factor for cataract formation. ${ }^{4}$ Revisiting the photochemistry of solar UVA in human skin, it was stated that the importance of UVA in skin cancer is undeniable, ${ }^{5,6}$ Cyclobutane pyrimidine dimers were detected in significant yield in whole human skin exposed to UVA radiation. ${ }^{7}$ UVA irradiation is also responsible for the most frequent photo-dermatosis of the skin. ${ }^{8}$ Recent epidemiological data showed that UVA radiation is even involved in the genesis of cutaneous melanoma. ${ }^{9}$

UVA radiation can penetrate deeper into tissue than UVB, which may lead to interaction with more tissue constituents as compared to UVB. However, UVA radiation is not sufficiently absorbed in proteins or DNA, which leads to different mechanisms of action in tissue for UVA and UVB. It is known that also UVA radiation leads to oxidative damage, single- and doublestrand breaks, produces secondary photoreactions, damages DNA by indirect photosensitizing reactions, and induces the photoproduct 8-oxo-7, 8-dihydro-2'-deoxyguanosine (8oxoG) in human skin. ${ }^{10}$

Department of Dermatology, University of Regensburg, 93042, Regensburg, Germany. E-mail: baeumler.wolfgang@klinik.uni-regensburg.de; Fax: +49941-944-9647; Tel: +49-941-944-9607

$\dagger$ Contribution to the themed issue on the biology of UVA.
Thus, UVA radiation acts indirectly by producing reactive oxygen species (ROS), in which the highly reactive singlet oxygen $\left({ }^{1} \mathrm{O}_{2}\right)$ plays a major role. ${ }^{3}$

\section{Photodynamic generation of singlet oxygen}

The first prerequisite of photodynamic generation of ${ }^{1} \mathrm{O}_{2}$ is the absorption of radiation in molecules (Fig. 1). These could be either endogenous photosensitizers or exogenous molecules, which are accidentally present in UVA exposed skin. ${ }^{11,12}$ Many molecules convert the absorbed energy simply to heat. However, after light absorption, some molecules can effectively cross over to a longlived triplet $T_{1}$ state. This is known as intersystem crossing (ISC). In contrast to the short-lived singlet $S_{1}$ state, which shows a lifetime in the order of nanoseconds, the triplet $T_{1}$ state is long-lived with lifetimes in the order of microseconds to milliseconds. This allows an efficient transfer of energy or charge to substrate or molecular oxygen generating radicals or ${ }^{1} \mathrm{O}_{2}$, respectively (Fig. 2).

These specific generation mechanisms of ROS comprise the same mechanisms as known in photodynamic therapy of tumors $(\mathrm{PDT})^{13}$ or in antimicrobial PDT (aPDT). ${ }^{14}$ Those molecules in tissue that convert the energy to reactive oxygen species (ROS) are called endogenous photosensitizers. Some of the endogenous photosensitizers in cells or tissue are identified such as flavins, ${ }^{15}$ NADH/NADPH,${ }^{16}$ urocanic acid, ${ }^{15,17}$ sterols, ${ }^{18}$ and anthraquinones. ${ }^{19}$

\section{Detection of singlet oxygen}

The detection of ${ }^{1} \mathrm{O}_{2}$, in particular when excited with UVA, is performed by using various methods that can be assigned to indirect and direct procedures. The main methods applied are the use of quenchers, measurement of ${ }^{1} \mathrm{O}_{2}$ luminescence, and electronic paramagnetic spin resonance (Table 1). 
Table 1 Singlet oxygen generation and detection under UVA exposure

\begin{tabular}{|c|c|c|c|}
\hline Authors & Photosensitizer & Environment & Detection \\
\hline Zhang et al. ${ }^{52}$ & thiopurine DNA bases & solution & luminescence \\
\hline Musson et al. ${ }^{50}$ & protein phosphatase calcineurin & in vitro & quencher \\
\hline Thomas et al. ${ }^{53}$ & pterins & solution & luminescence \\
\hline Baier et al. ${ }^{15}$ & urocanic acid, flavins & solution & luminescence \\
\hline Avalle et $a l^{49}$ & lipofuscin & solution & luminescence \\
\hline Lamore $^{51}$ & protein epitope dihydropyridine (DHP)-lysine & solution & RNO bleaching $^{b}$ \\
\hline Yin et al. ${ }^{54}$ & anhydroretinol & solution & $\mathrm{EPR}^{a}$ \\
\hline Agrawal et al. ${ }^{25}$ & Ciprofloxacin & in vitro & RNO bleaching \\
\hline Ray et al. ${ }^{57}$ & fluoroquinolones & solution & RNO bleaching \\
\hline Jantova et al. ${ }^{56}$ & quinolones & in vitro & EPR \\
\hline Barbierikova et al. ${ }^{58}$ & Selenadiazoloquinolones & solution & EPR \\
\hline Martinez et al. ${ }^{60}$ & NSAID & solution & luminescence \\
\hline Vargas et al. ${ }^{61}$ & levomepromazine & solution & quencher \\
\hline Bilski et al. ${ }^{62}$ & antiepileptic drug Lamotrigine & solution & luminescence \\
\hline Wolnicka et al ${ }^{63}$ & neuroleptic drug Chlorpromazine & solution & luminescence \\
\hline Onoue et al. ${ }^{64}$ & imidazopyridine derivatives & solution & RNO bleaching \\
\hline Bao et al. ${ }^{68}$ & polycyclic aromatic hydrocarbons (PAH) & in vitro & quencher \\
\hline Regensburger $^{12}$ & polycyclic aromatic hydrocarbons & solution & luminescence \\
\hline Zhao et al. ${ }^{67}$ & fullerene & solution, in vitro & EPR, quencher \\
\hline Baier et al. ${ }^{36}$ & skin constituents & in vivo & luminescence \\
\hline
\end{tabular}

${ }^{a}$ EPR: electron paramagnetic resonance spectroscopy. ${ }^{b}$ Absorbance decrease of $N, N$-dimethyl-4-nitrosoaniline at $440 \mathrm{~nm}$.

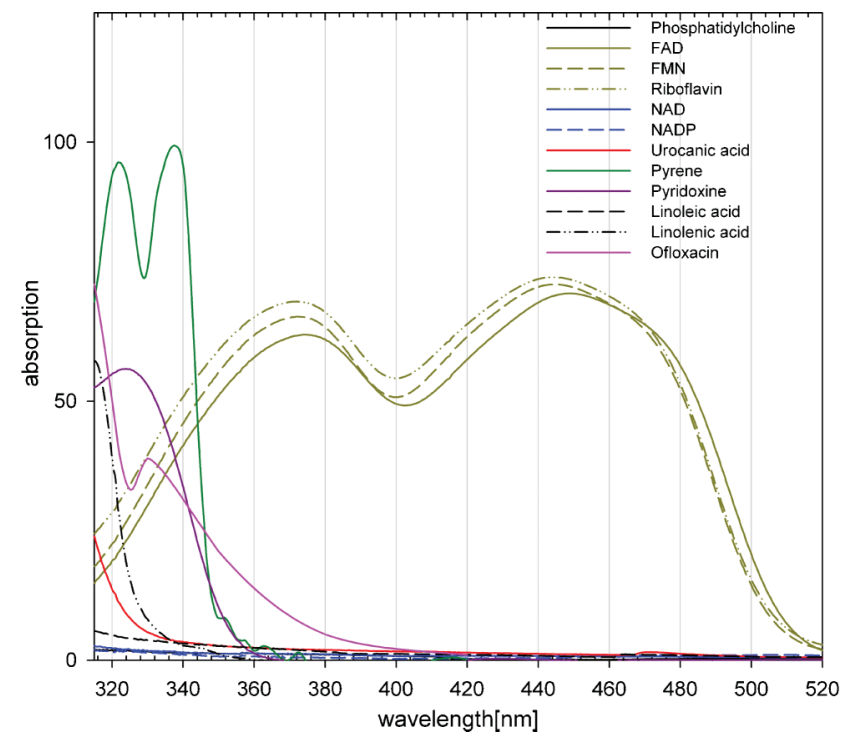

Fig. 1 The absorption of some molecules that may act as endogenous photosensitizers to generate singlet oxygen. For a better illustration, absorption is given in percent (absorption $=100 \%-$ transmission). The values are measured with spectrophotometer (Beckman, DU 640) in polar or nonpolar solvents at a concentration of $50 \mu \mathrm{mol} \mathrm{L} \mathrm{L}^{-1}$, except for phosphatidylcholine $\left(2.2 \mathrm{mmol} \mathrm{L}^{-1}\right)$, fatty acids $(10 \mathrm{mM})$, ofloxacin $(10$ $\mu \mathrm{g} \mathrm{ml}^{-1}$ ) and pyridoxine $(200 \mu \mathrm{M})$. The fatty acids (purity: $99 \%$ ) contain traces of oxidized products that enables absorption of UVA radiation. Two substances were exemplarily added to the figure that may be present in skin accidentally and can act as UVA photosensitizer: pyrene (in black tattoo inks), ofloxacin (systemic treatment with antibiotics).

\section{Indirect detection}

An important indirect proof of ${ }^{1} \mathrm{O}_{2}$ is the chemical analysis of its reaction products, ${ }^{20-22}$ although this method frequently yields no unequivocal results. Specific quenchers such as sodium azide shorten the lifetime of ${ }^{1} \mathrm{O}_{2}$, whereas the use of the solvent deuterium oxide $\left(\mathrm{D}_{2} \mathrm{O}\right)$ extends the lifetime of ${ }^{1} \mathrm{O}_{2}$. By shortening

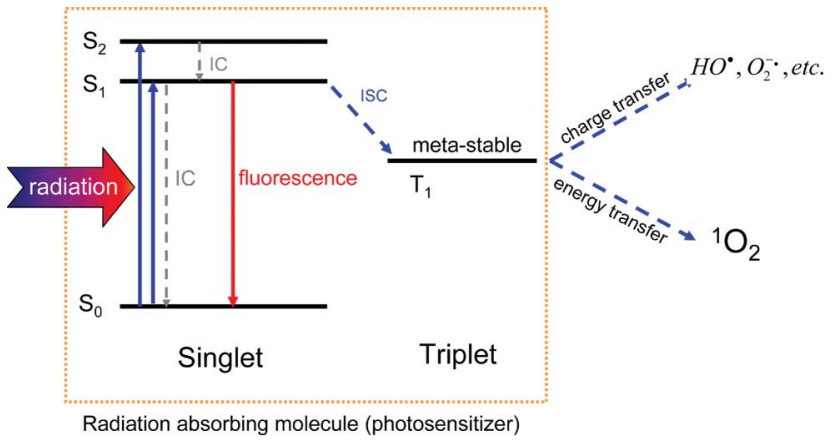

Fig. 2 The scheme shows the generation of reactive oxygen species that is initiated by radiation absorption in a photosensitizer molecule. The absorption leads to population of excited singlet states in the molecule, which rapidly (picoseconds) yields $\mathrm{S}_{1}$ population via internal conversion (IC). Within nanoseconds, the absorbed energy is either converted to heat (IC) or to fluorescence. A third pathway is the intersystem crossing (ISC) in the molecule to the metastable triplet $T_{1}$ state (lifetime: $\mu$ s to ms), which allows energy or charge transfer to other molecules such as oxygen.

or extending the ${ }^{1} \mathrm{O}_{2}$ lifetime, the related damage of cellular structures is reduced or pronounced, which can be detected with different cellular parameters (e.g. mitochondrial activity or cell survival). ${ }^{23}$ When adding spin traps, ESR signals show the presence of ${ }^{1} \mathrm{O}_{2} \cdot{ }^{24} \mathrm{In}$ addition, ${ }^{1} \mathrm{O}_{2}$ can be detected by exploiting its chemical reactivity in different settings such as RNO-bleaching ${ }^{25,26}$ or chemoluminescence assays. ${ }^{27}$ The chemoluminescence assays are frequently based on switch-on fluorescence of rhodamines or fluoresceins such as ' ${ }^{1} \mathrm{O}_{2}$ Sensor Green (SOSG)'.

Except for chemical analysis, the disadvantages of these indirect methods are obvious since they require the application of reporter molecules, which may show limited access to living cells in vitro. It is hence not warranted that the quencher reach the site of ${ }^{1} \mathrm{O}_{2}$ concentration with an appropriate concentration. The application in vivo is also limited because some of these substances are toxic or do not penetrate tissue to a sufficient extent. 


\section{Direct detection}

The non-radiative deactivation of ${ }^{1} \mathrm{O}_{2}$ is accompanied by radiative deactivation yielding infrared luminescence at about $1270 \mathrm{~nm}$. The luminescence detection is a great tool to directly detect ${ }^{1} \mathrm{O}_{2}$ without adding any reporter molecules, in particular for experiments with UVA radiation (Fig. 3). This technology can be applied for experiments in solution, in vitro and in vivo.

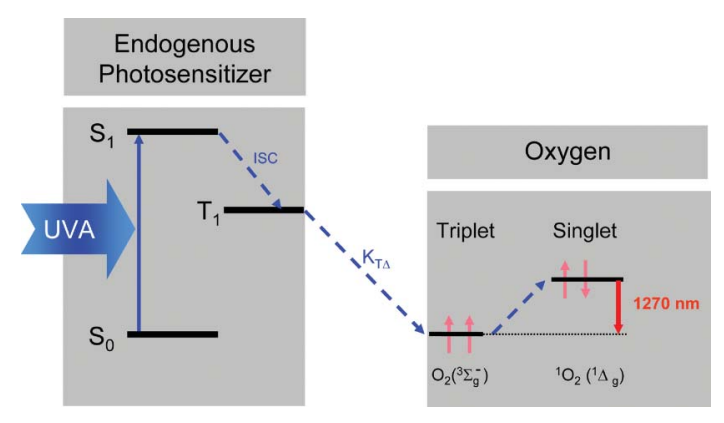

Fig. 3 The rate constant $K_{\mathrm{T} \Delta}$ describes the formation of ${ }^{1} \mathrm{O}_{2}$, which corresponds to the transition from the molecular oxygen ground state (triplet state) to its first singlet state. ${ }^{1} \mathrm{O}_{2}$ can be detected by its weak luminescence that occurs at $1270 \mathrm{~nm}$.

The major disadvantage of luminescence detection is the very low quantum yield of the radiative decay in the order of $10^{-7}$, which requires a very sensitive detection system. For more than 10 years, however, special photomultipliers have been available that show a high sensitivity in the infrared spectrum up to $1400 \mathrm{~nm}$. Now, these photomultipliers are successfully and frequently used for ${ }^{1} \mathrm{O}_{2}$ detection. ${ }^{28-34}$

Several groups world-wide have undertaken much effort to optimize the detection technology and to gain more detailed information from such ${ }^{1} \mathrm{O}_{2}$ luminescence signals. ${ }^{35}$ The detection of ${ }^{1} \mathrm{O}_{2}$ luminescence in living cells or tissue has proven to be a technically challenging problem for the following reasons. Due to low oxygen concentrations, ${ }^{29,36}$ short ${ }^{1} \mathrm{O}_{2}$ lifetime, ${ }^{37}$ and changing oxygen diffusion coefficients in cells or tissue, ${ }^{28}$ the signal intensity may be substantially weaker than in solution, showing diverse rates. Scattering in turbid media, e.g. cell suspensions, may lead to an increased superposition of the signals with other radiation sources, which was recently investigated by the groups of Wilson ${ }^{29}$ and Röder. ${ }^{28}$ In addition, flash photolysis experiments can be applied for triplet spectroscopy and the results can be compared to singlet oxygen luminescence at $1270 \mathrm{~nm} .{ }^{28}$ Spatially resolved singlet oxygen luminescence were detected either on a microscopic scale, in particular in living cells, ${ }^{38}$ or in vivo using a scanning laser system. ${ }^{39}$

\section{Time-resolved luminescence detection}

Using excitation lasers with short pulse durations and $\mathrm{kHz}$ repetition rates, along with the highly sensitive IR photomultipliers, the single photon counting allows very sensitive luminescence detection with a high time resolution. This technique, meanwhile rather standardized, shows advantages over the conventional analogue detection mode that was used in the past. ${ }^{40}$

To generate ${ }^{1} \mathrm{O}_{2}$ by UVA radiation, the emission of a frequency tripled $\mathrm{Nd}$ :YAG laser (355 $\mathrm{nm}$ ) or an appropriate OPO laser can be applied to excite endogenous photosensitizers. The laser pulse energy for luminescence experiments should be kept low (a few $\mu \mathrm{J})$ to minimize the damage of photosensitizer and cellular structures. ${ }^{28}$ The ${ }^{1} \mathrm{O}_{2}$ luminescence at $1270 \mathrm{~nm}$ can be detected in either perpendicular or near-backward direction with respect to the excitation beam using infrared sensitive photomultipliers (e.g. Hamamatsu). ${ }^{15,28,29,33,38}$ To avoid detection of non- ${ }^{1} \mathrm{O}_{2}$ photons, appropriate interference filters and cut-off-filters are usually placed in front of the photomultiplier (Fig. 4).

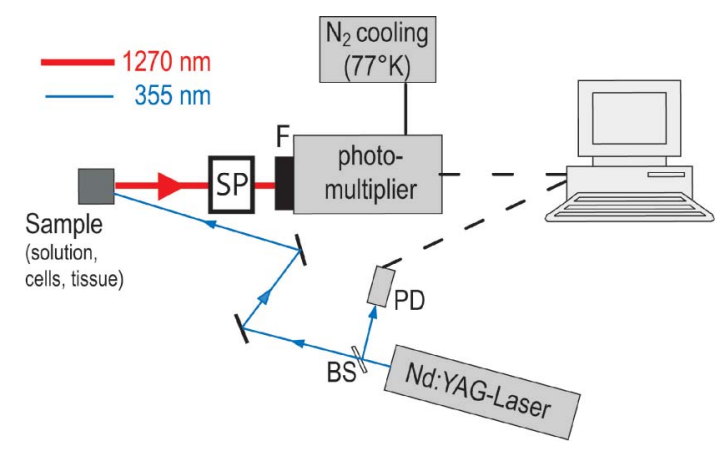

Fig. 4 A schematic setting for detection of singlet oxygen luminescence. The sample is excited with a frequency tripled Nd:YAG laser that emits at $355 \mathrm{~nm}$. The luminescence is collected and transferred to the infrared sensitive photomultiplier, which is equipped with a $1270 \mathrm{~nm}$ interference filter. The single photon counting setting enables the time-resolved detection, whereas the stop signal is provided by a photodiode (PD): via beam splitter (BS). The spectral resolution is either achieved with different interference filters from 1100 to $1400 \mathrm{~nm}$ or by using a spectrometer (SP).

\section{Spectrally resolved luminescence detection}

Due to the very low luminescence signals, which is potentially superposed by other near infrared signal such as fluorescence or phosphorescence, it is important to detect the luminescence signal spectrally resolved in order to confirm that the signal can be attributed to ${ }^{1} \mathrm{O}_{2} .{ }^{29,41,42}$ When combining the time- and spectrally resolved luminescence, the resulting 3D-image provides evidence for clear luminescence signal of ${ }^{1} \mathrm{O}_{2}$, an example is displayed in Fig. 5.

\section{Mathematical fit of time-resolved singlet oxygen luminescence}

After detection of such time resolved signals, it is a first and practical step to fit the gained signal curve using a constant $C$, the rise $\left(\tau_{\mathrm{R}}\right)$ and decay $\left(\tau_{\mathrm{D}}\right)$ times as well as different fit routines such as least square fit. ${ }^{43}$

$$
I(t)=\frac{C}{\tau_{\mathrm{R}}^{-1}-\tau_{\mathrm{D}}^{-1}}\left[\exp \left(-\frac{t}{\tau_{\mathrm{D}}}\right)-\exp \left(-\frac{t}{\tau_{\mathrm{R}}}\right)\right]
$$

When applying different experiments, the values can be attributed to the respective rates and rate constants in the respective experiment. ${ }^{42}$ The counted luminescence photons can be summed to calculate the total amount of ${ }^{1} \mathrm{O}_{2}$ detected. The spectrally resolved luminescence signal, either using a monochromator ${ }^{34}$ or different interference filters, ${ }^{36}$ is fitted with a Lorentzian function.

The time resolved luminescence signal provides information about the generation and deactivation of ${ }^{1} \mathrm{O}_{2}$ in its present environment. The in-depth evaluation of time-resolved luminescence signals can be performed along with mathematical equations, which describe the generation and decay of ${ }^{1} \mathrm{O}_{2} \cdot{ }^{29,42}$ Briefly, the coupling of a photosensitizer molecule with molecular oxygen via 


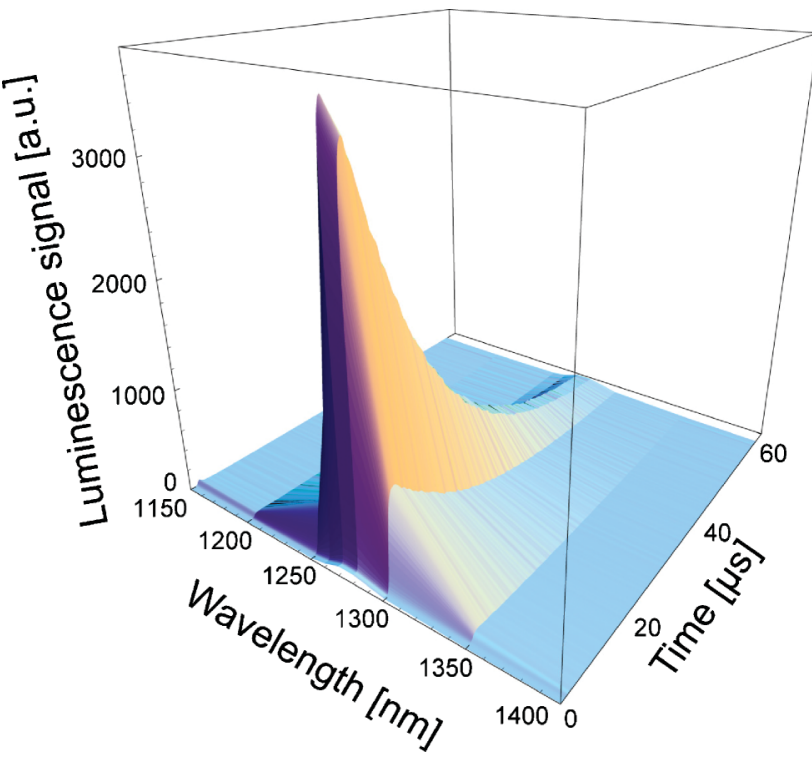

Fig. 5 The time- and spectrally resolved signal can be combined to have a clear confirmation of ${ }^{1} \mathrm{O}_{2}$ signal. This is important in case of weak luminescence signals, in particular from cells and tissue.

energy transfer from its triplet $T_{1}$ state to molecular oxygen yields a coupled system of differential equations, which can be reduced to the rate constants of the triplet $\mathrm{T}_{1}$ state or first ${ }^{1} \mathrm{O}_{2}$ state:

$$
\begin{gathered}
\frac{\mathrm{d}\left[\mathrm{T}_{1}\right]}{\mathrm{d} t}=-K_{T}\left[\mathrm{~T}_{1}\right] \\
\frac{\mathrm{d}\left[{ }^{1} \mathrm{O}_{2}\right]}{\mathrm{d} t}=-K_{\Delta}\left[{ }^{1} \mathrm{O}_{2}\right]
\end{gathered}
$$

The signal will rise with the largest of the two rates and decay with the lowest. The assignment of the measured rise $\left(\tau_{\mathrm{R}}\right)$ and decay $\left(\tau_{\mathrm{D}}\right)$ times to the rates of ${ }^{1} \mathrm{O}_{2}$ or photosensitizer $\mathrm{T}_{1}$ state remains challenging.

In non-viscous media (e.g. solvents), for high oxygen concentrations, the rise time is equivalent to $K_{\mathrm{T}}$ and the decay time to $K_{\Delta}$, whereas for small oxygen concentrations it is the other way around. After this classification, the rates can be assigned to the respective lifetimes. In highly viscous media (e.g. in cells or tissue), the diffusion of oxygen molecules plays an additional role that complicates the evaluation of time resolved measurements and the assignment of the lifetimes.

The rates are intrinsically tied to the concentration and diffusion of oxygen in the environment of ${ }^{1} \mathrm{O}_{2}$ production. When evaluating such luminescence signals, it is therefore important to know, to measure or to estimate the oxygen concentration at the site of ${ }^{1} \mathrm{O}_{2}$ production during luminescence detection. In solution or cell suspensions, small needle sensors can be applied to monitor the oxygen concentration. ${ }^{44}$

\section{Quantification of singlet oxygen}

To quantify the ${ }^{1} \mathrm{O}_{2}$ generation of endogenous photosensitizers, the quantum yield $\Phi_{\Delta}$ can be determined by using the Wilkinson definition $^{45}$ or by comparing the luminescence signals of the photosensitizer with unknown $\Phi_{\Delta}$ to photosensitizer with known $\Phi_{\Delta}{ }^{15}$ Values are listed for a selection of photosensitizers in

\begin{tabular}{|c|c|c|}
\hline Photosensitizer & Category & $\Phi_{\Delta}$ \\
\hline $11-$ cis retinal $^{93}$ & vitamin $\mathrm{A}$ & 0.55 \\
\hline Riboflavin $^{15}$ & vitamin $\mathrm{B}_{2}$ & 0.54 \\
\hline Riboflavin $^{94 b}$ & vitamin $\mathrm{B}_{2}$ & 0.49 \\
\hline $\mathrm{FMN}^{15}$ & vitamin $\mathrm{B}_{2}$ & 0.51 \\
\hline $\mathrm{FAD}^{15}$ & vitamin $\mathrm{B}_{2}$ & 0.07 \\
\hline Pyridoxal $^{95}$ & vitamin $\mathrm{B}_{6}$ & 0.44 \\
\hline Pyridoxine ${ }^{95}$ & vitamin $\mathrm{B}_{6}$ & 0.28 \\
\hline Pyridoxamine $^{95}$ & vitamin $\mathrm{B}_{6}$ & 0,06 \\
\hline Pyrocobester ${ }^{96}$ & vitamin $B_{12}$ & 0.21 \\
\hline Vitamin $\mathrm{E}^{97 a}$ & vitamin $\mathrm{E}$ & 0.10 \\
\hline Ergosterol $^{98}$ & provitamin $\mathrm{D}_{2}$ & 0.85 \\
\hline Lipofuscin $^{99}$ & aging pigment & 0.08 \\
\hline Naproxen $^{60}$ & NSAID & 0.28 \\
\hline Nabumetone ${ }^{60}$ & NSAID & 0.19 \\
\hline Ciprofloxacin ${ }^{100}$ & antibiotics & 0.09 \\
\hline Ofloxacin ${ }^{100}$ & antibiotics & 0.08 \\
\hline Anthracene ${ }^{12}$ & PAH & 0.81 \\
\hline Chlorpromazine $^{101}$ & neuroleptics & 0.27 \\
\hline Lamotrigine $^{62}$ & antiepileptics & 0.22 \\
\hline Hypericin $^{102}$ & antidepressants & 0.43 \\
\hline 6-thioguanine ${ }^{52}$ & immunosuppression & 0.56 \\
\hline Pterin $^{53 c}$ & UV receptors & 0.30 \\
\hline
\end{tabular}

Table 2 UVA-induced $\Phi_{\Delta}$ measured by means of luminescence detection

${ }^{a} 308 \mathrm{~nm}$ excitation. ${ }^{b}$ indirect (EPR, RNO-bleaching). ${ }^{c} \mathrm{pD}=10.5$.

Table 2. It should be noted that the quantum yields are predominantly determined for photosensitizers in aerated solvents. In case of low oxygen concentrations (e.g. inside cells or tissue), $\Phi_{\Delta}$ values may clearly differ from those values as shown in Table 2 . For example, $\Phi_{\Delta}$ of Riboflavin in solution decreases from 0.54 (oxygen concentration: $280 \mu \mathrm{M}$ ) to about 0.20 (oxygen concentration: $2 \mu \mathrm{M}$ ). ${ }^{15}$ This decrease can be different for different photosensitizers.

\section{Photosensitized generation of singlet oxygen}

In contrast to UVB, UVA radiation mainly provokes photosensitized reactions. ${ }^{46}$ The major prerequisite of photosensitized reactions is UVA absorption in such molecules. The list of molecules has been fairly extended during recent years. It starts with endogenous porphyrins of heme synthesis, flavins, and the cellular pyrimidine nicotinamide cofactors (NADH and NADPH). ${ }^{47}$ Meanwhile, the list also contains exogenous molecules, which are frequently administered to skin along with medical treatments. The papers cited below represent a non-exhausting selection of endogenous photosensitizers.

\section{Endogenous photosensitizers}

Among others, endogenous porphyrin molecules such as Protoporphyrin IX, the precursor of heme, efficiently generate ${ }^{1} \mathrm{O}_{2}$ under UVA irradiation leading to activation of heme oxygenase-1 (HO-1). ${ }^{48}$

Urocanic acid produces ${ }^{1} \mathrm{O}_{2}$ with UVA irradiation $(355 \mathrm{~nm})$ that was directly proven by luminescence signal. ${ }^{15}$ In the same work, excitation with UVA of Riboflavin, FMN and FAD yielded strong luminescence signals and the respective quantum yields could be determined with $\Phi_{\Delta}=0.54$ (riboflavin), $\Phi_{\Delta}=0.51(\mathrm{FMN})$, and $\Phi_{\Delta}=0.07$ (FAD). Depending on their concentration in the skin, the flavins are potential generators of ${ }^{1} \mathrm{O}_{2}$, even more effective than exogenous porphyrins used for cell killing in photodynamic therapy. In view of these high values, it seems to be reasonable that 
these substances, even though at low concentrations, can provide sufficient amount of ${ }^{1} \mathrm{O}_{2}$ during UVA exposure that leads to gene regulation, photoaging, and possibly carcinogenesis.

The human retinal pigment epithelial (RPE) layer contains a complex mixture of components called lipofuscin; this mixture forms with age and with various genetic disorders such as Stargardt's disease. It is well accepted that lipofucsin generates ${ }^{1} \mathrm{O}_{2}$ when excited with UVA, which contributes to retinal maculopathies. ${ }^{49}$

The protein phosphatase calcineurin has been gradually revealing itself as the central controller of our immune response. UVA1 radiation suppresses calcineurin activity. Evidence was provided that this activity loss is partly due to ${ }^{1} \mathrm{O}_{2}$ generated by photosensitization. ${ }^{50}$ Recently, experiments showed that the malondialdehyde-derived protein epitope dihydropyridine (DHP)lysine is a potent endogenous UVA-photosensitizer of human skin cells. $^{51}$

The photophysics and photochemistry of thiopurine DNA bases are far less understood than those of normal DNA bases, although some of them, such as azathioprine, 6-mercaptopurine, and 6-thioguanine, have been used as cancer therapeutic and immunosuppressive agents for five decades. The incorporation of 6-thioguanine into DNA increases the risk of ${ }^{1} \mathrm{O}_{2}$-initiated skin cancer. It was very recently shown that UVA irradiation of 6thioguanines in solution produced ${ }^{1} \mathrm{O}_{2}$ with quantum yields $\Phi_{\Delta}$ from 0.49 to $0.58 .^{52}$ 6-Thioguanines absorb UVA radiation in a broad range from $320-370 \mathrm{~nm}$ with a maximum at around $340 \mathrm{~nm}$.

Pterins (2-amino-4-hydroxypteridin derivatives) are a family of heterocyclic compounds present in a wide variety of biological systems. Pteroyl-L-glutamic acid (folic acid) is a precursor of coenzymes involved in the metabolism of nucleotides and amino acids. All investigated pterins produced significantly amounts of ${ }^{1} \mathrm{O}_{2}$ with $\Phi_{\Delta}$ in the range from 0.30 to 0.47 (pD Value 10.5). Only folic acid showed a very small quantum yield of less than $0.02 .{ }^{53}$

Anhydroretinol is a metabolite of vitamin A (retinol) and a major photodecomposition product of retinyl palmitate and retinyl acetate. There is sufficient evidence that irradiation of anhydroretinol with UVA light generates reactive oxygen species, e.g. ${ }^{1} \mathrm{O}_{2}$, which mediate the induction of lipid peroxidation. ${ }^{54}$

Fluorescent proteins are increasingly applied in different sections of experimental biology. One of those techniques is chromophore-assisted laser inactivation, which is employed to specifically inactivate the function of target proteins or organelles by producing photochemical damage. ${ }^{55}$ Using time resolved luminescence detection, singlet oxygen was proven to be generated by the red fluorescent protein TagRFP with an estimated quantum yield of 0.004 .

\section{Antibiotics}

Many substances, which are used in antibiotics such as quinoline derivatives, ${ }^{56}$ are known to generate ${ }^{1} \mathrm{O}_{2}$ under UVA exposure. Ciprofloxacin produced ROS by Type I and Type II photodynamic reactions, interacted with nucleic acid moiety and inhibited cell viability. ${ }^{25}$ The production of ${ }^{1} \mathrm{O}_{2}$ by various antibiotics was found to be concentration dependent. In the fluoroquinolone group, enoxacin generated most ${ }^{1} \mathrm{O}_{2}$ under UVA irradiation followed by lomefloxacin, norfloxacin, and ofloxacin. ${ }^{57}$ In light of the undesirable photosensitized reactions of fluoroquinolones, new selenium-containing heterocyclic compounds were investigated. However, also these substances produced ${ }^{1} \mathrm{O}_{2}{ }^{58}$

\section{Other medical drugs}

Several classes of drugs including thiazide diuretics, nonsteroidal anti-inflammatory drugs (NSAIDs), and tricyclic antidepressants, even when not toxic by themselves, may become reactive under exposure to environmental radiation, inducing undesired side effects. Providing a few examples, the following section should highlight the problems with ${ }^{1} \mathrm{O}_{2}$ that is generated by medical drugs exposed to UVA.

Nonsteroidal anti-inflammatory drugs (NSAIDs) are a chemically heterogeneous group of drugs mainly used as antiinflammatory particularly in the treatment of rheumatic diseases. Some of the NSAID are potent photosensitizers when exposed to UVA radiation. ${ }^{59}$ Due to the presence of the naphthalene chromophore, substances like Nabumetone or Naproxen generate ${ }^{1} \mathrm{O}_{2}$ with quantum yields of 0.19 or 0.28 in solution. ${ }^{60}$

The neuroleptic drug levomepromazine (known as methotrimeprazine) is photolabile under UVA and UVB radiation in aerobic conditions. Irradiation of a methanol solution of this drug produces one photoproduct, resulting from oxidation. It is demonstrated that photodegradation occurs via type II mechanism involving irreversible trapping of self-photogenerated singlet molecular oxygen. ${ }^{61}$ Lamotrigine (LTG) is an anticonvulsant (antiepileptic) drug specifically blocking voltage-gated sodium channels. LTG occasionally causes cutaneous problems including exaggerated sunburn or skin photo-irritation. Depending on the solvent, the quantum yield $\Phi_{\Delta}$ of LTG shows values up to $0.22 .{ }^{62}$ Chlorpromazine (CPZ), a phenothiazine derivative, is a neuroleptic drug widely used in medicine because of its tranquilizing and antipsychotic properties. Experimental data indicate that in hydrophobic environment CPZ is a relatively efficient generator of ${ }^{1} \mathrm{O}_{2} \cdot{ }^{63}$

Imidazopyridine derivatives are designed as $5-\mathrm{HT}_{4}$ receptor agonist for the clinical treatment of gastroesophageal reflux disease. Also these substances produce ${ }^{1} \mathrm{O}_{2}$ under UVA exposure. ${ }^{64}$ Dihydropyridine-type calcium channel antagonists such as nifedipine and nitrendipine are important drugs for the treatment of hypertension and coronary heart disease. A novel substance and some of the derivates produced significant amounts of ${ }^{1} \mathrm{O}_{2}$ under simulated solar radiation. ${ }^{65}$

Nano-materials such as water-soluble fullerenes have shown potential uses as drug carriers to bypass the brain and ocular barriers. However, photoexcitation of fullerene derivatives may produce ${ }^{1} \mathrm{O}_{2}{ }^{66}$ The water-soluble fullerene derivative $\gamma$ cyclodextrin bicapped $\mathrm{C}_{60}$ efficiently generates ${ }^{1} \mathrm{O}_{2}$ under UVA exposure. Since this compound has an absorbance maximum of $349 \mathrm{~nm}$, it has the potential to cause lenticular damage when in the human eye. ${ }^{67}$

\section{Other exogenous compounds}

Polycyclic aromatic hydrocarbons (PAHs) are widely spread substances in environment that have been identified as essential risk factors for various benign or malignant human diseases, either alone or in combination with UVA. Specific sources are cigarette smoke and diesel particles extracts (DPE). In vitro experiments 
showed that sodium azide significantly inhibited both cellular and DNA damage induced by DPE + UVA treatment, which provide evidence of ${ }^{1} \mathrm{O}_{2}$ generation by PAHs ${ }^{68}$

PAHs are injected into the skin along with black tattoo inks and may stay intradermally for years. After incubation of skin cells with extracts of black tattoo inks, the cells were exposed to UVA and cell viability decreased in a dose-dependent manner. The quantum yield $\Phi_{\Delta}$ of different PAHs were determined yielding high values of up to 0.85 for benz[a]anthracene. ${ }^{12}$

Nanoparticles such as silicon nanoparticles can generate ${ }^{1} \mathrm{O}_{2}$ on its surface via energy transfer from an exciton singlet state to oxygen. ${ }^{69}$ This might be of particular interest when using nanoparticles in ointments and medical drugs.

\section{UVA-mediated singlet oxygen generation}

Besides the photosensitized generation triggered by UVA, ${ }^{1} \mathrm{O}_{2}$ can be produced by various chemical reactions involving different radicals and other reactive species. ${ }^{70}$ In the presence of oxidizable biomolecules like lipids, proteins or DNA, photosensitization and chemical reactions (e.g. lipid peroxidation) may occur at the same time yielding various products. ${ }^{71,72}$

Usually lipids and fatty acids are the target of ${ }^{1} \mathrm{O}_{2}$ that has been generated by any photosensitizer. However, we have shown that ${ }^{1} \mathrm{O}_{2}$ is generated in suspensions of egg yolk phosphatidylcholine during irradiation with UVA that included the action of oxygen radicals. ${ }^{36}$ Under $355 \mathrm{~nm}$ irradiation, different fatty acids (oleic acid 18:1, linoleic acid 18:2, linolenic acid 18:3) in aerated ethanol solution $\left(50 \mathrm{mmol} \mathrm{L}{ }^{-1}\right.$ each) showed clear ${ }^{1} \mathrm{O}_{2}$ luminescence signals, without any photosensitizer (Fig. 6), which was confirmed by the spectrally resolved detection of the signals (Fig. 7). The decay time of the signal $\tau_{\Delta}=\left(K_{\Delta}\right)^{-1}$ was in the range from 13 to $14 \mu \mathrm{s}$, which is the life time of ${ }^{1} \mathrm{O}_{2}$ in ethanol. ${ }^{42}$

Oxidized products of such fatty acids must be present to enable initial absorption of UVA radiation. ${ }^{73}$ Once singlet oxygen is generated, the amount of oxidized products increases, which in turn enhances radiation absorption. Usually, luminescence signals of photosensitizer induced ${ }^{1} \mathrm{O}_{2}$ show a rise time and a decay time according to the eqn (1)-(3). However, time-resolved luminescence signals of ${ }^{1} \mathrm{O}_{2}$ in fatty acid solutions showed a decay time but no rise time. That is, the luminescence signal was maximal within a time span of less than $200 \mathrm{~ns}$. The difference of such signals shapes, with and without rise time, is illustrated in Fig. 8. A photosensitized generation of ${ }^{1} \mathrm{O}_{2}$ by a porphyrin photosensitizer in water shows a clear rise time, which is $\tau_{\mathrm{T}}=\left(K_{\mathrm{T}}\right)^{-1}=1.9 \mu \mathrm{s}$, whereas the decay time was $\tau_{\Delta}=\left(K_{\Delta}\right)^{-1}=3.6 \mu \mathrm{s}$. We suggested that due to the lack of rise time, the light absorbing molecules are not able to form such a triplet state (e.g. linear-shaped molecules like fatty acids). Thus, we assumed that ${ }^{1} \mathrm{O}_{2}$ is generated with the assistance of chemical reactions, but initiated by the applied UVA radiation. ${ }^{74}$

In addition, hydroperoxides of fatty acids can be further decomposed to acid-peroxyl radicals and/or alkoxyl radicals, which are responsible for the propagation of peroxidation. ${ }^{75}$ The decomposition of lipid hydroperoxides into peroxyl radicals has been shown to be a potential source of ${ }^{1} \mathrm{O}_{2}$ in biological systems. ${ }^{3,76}$ In 1957, Russell proposed a self-reaction mechanism of such peroxyl radicals involving the formation of a cyclic mechanism from a linear tetraoxide intermediate that decomposes to give different products as well as ${ }^{1} \mathrm{O}_{2} \cdot{ }^{77}$ It could be demonstrated that
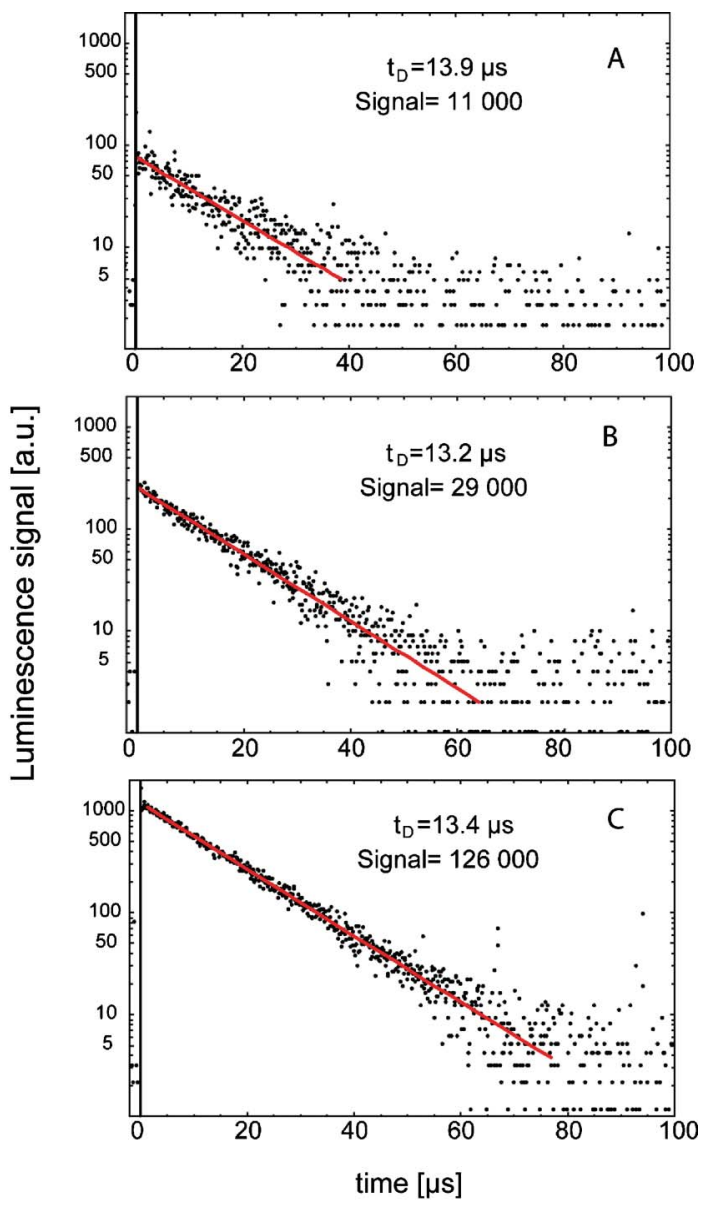

Fig. 6 The time-resolved ${ }^{1} \mathrm{O}_{2}$ luminescence signals of different fatty acids, oleic acid 18:1 (A), linoleic acid 18:2 (B), linolenic acid 18:3 (C) in aerated ethanol solution at $50 \mathrm{mmol} \mathrm{L}^{-1}$. The decay time $t_{\mathrm{D}}$ and the values of integrated signal are shown (Signal, arbitrary units).

such a self-reaction formation of peroxyl radicals deriving from fatty acids generates predominantly ${ }^{1} \mathrm{O}_{2} \cdot{ }^{78} \mathrm{Fig} .9$ shows a scheme of UVA-mediated generation of ${ }^{1} \mathrm{O}_{2}$ generation in fatty acids, which is probably not yet complete.

Such fatty acids are major constituents of many cellular membranes that should underline their potential role in UVA mediated activation of cellular signaling. Skin contains sufficient amount of oxygen $\left(p \mathrm{O}_{2} \sim 20\right.$ Torr) ${ }^{79}$ When exposed to UVA radiation, initial concentrations of oxidized fatty acids are present in $\operatorname{skin}^{80,81}$ to initiate the generation of ${ }^{1} \mathrm{O}_{2}$ (see Fig. 9). In cells, a molecule such as ceramide is a key component of stress responses. UVA radiation and ${ }^{1} \mathrm{O}_{2}$ both generated ceramide in protein-free, sphingomyelincontaining liposomes. ${ }^{82}$ Furthermore, human skin, especially the stratum corneum, contains free saturated and unsaturated fatty acids with mostly chain lengths of $\mathrm{C}_{16}$ to $\mathrm{C}_{18}$ atoms. ${ }^{83}$

Fatty acids are also constituents of creams and ointments, in particular used in sunscreens that protect skin from solar UV radiation. When exposing different creams or ointments in ethanol solution to UVA laser radiation at $355 \mathrm{~nm}$, we detected a clear and impressive signal of ${ }^{1} \mathrm{O}_{2}$ generation in many of the samples investigated. As for experiments with fatty acids, the decay time of ${ }^{1} \mathrm{O}_{2}$ was about $14 \mu$ s according to the used solvent ethanol. The maximum signal intensity among the investigated creams yielded 


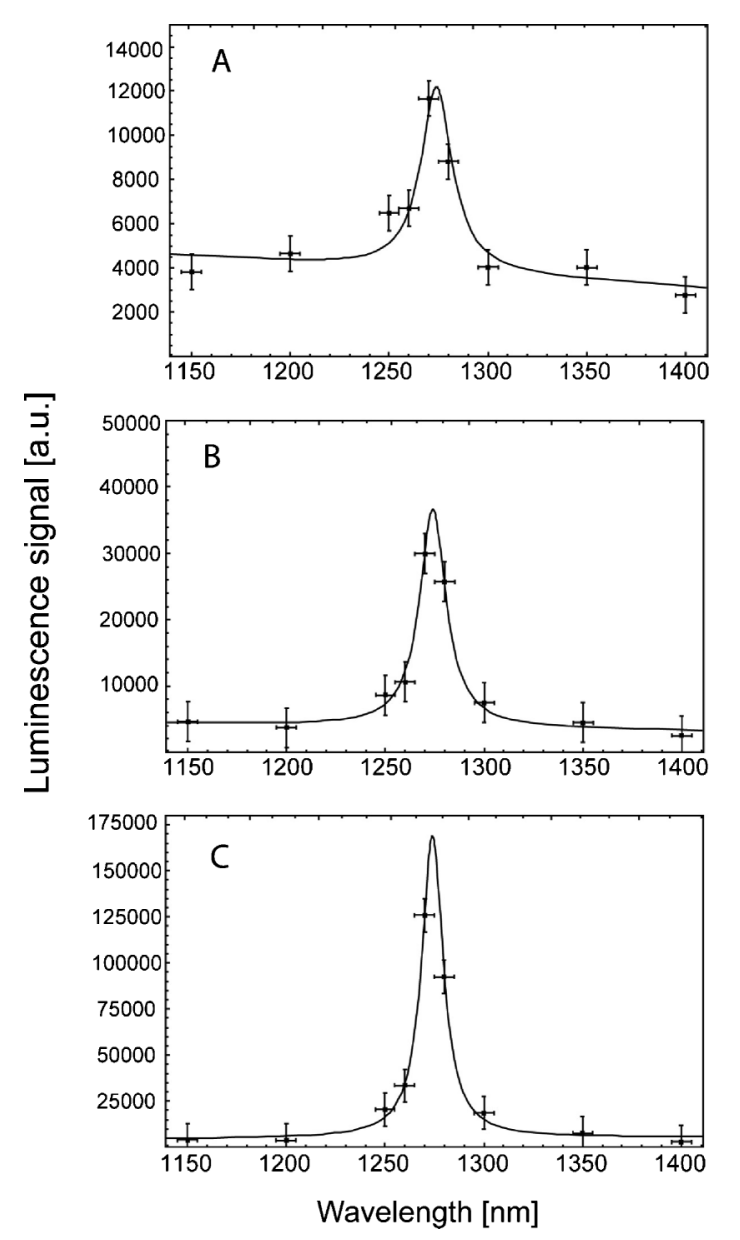

Fig. 7 The spectrally resolved ${ }^{1} \mathrm{O}_{2}$ luminescence signals of different fatty acids, oleic acid 18:1 (A), linoleic acid 18:2 (B), linolenic acid 18:3 (C) in aerated ethanol solution at $50 \mathrm{mmol} \mathrm{L}^{-1}$. All signals show the transition of ${ }^{1} \mathrm{O}_{2}$ at $1270 \mathrm{~nm}$.

the sample shown in Fig. 10. The impact of such photosensitizing compounds, which are topically administered to skin and exposed to solar radiation, should be elucidated.

\section{Detection of singlet oxygen generation in skin}

Solar ultraviolet A (UVA; 320-400 $\mathrm{nm}$ ) radiation is a wellknown trigger of signaling responses in dermal fibroblasts in human skin in vivo. ${ }^{48,84}$ Investigations have been performed to assess the contribution of ${ }^{1} \mathrm{O}_{2}$ to lipid peroxidation under in vivo conditions. It is known that the generation of ${ }^{1} \mathrm{O}_{2}$ in turn activates interstitial collagenase like matrix-metalloproteinases (MMPs) ${ }^{80,85}$ such as MMP-1, which causes extracellular protein degradation and thereby contributes to photoaging of human skin. ${ }^{86}$ The activation of MMP-9 is an essential step in the skin photoaging on exposure to ultraviolet A (UVA). MMP-9 activity is clearly related to the presence of cholesterol-hydroperoxides such as cholesterol $5 \alpha$-hydroperoxide, which is specifically occurs with ${ }^{1} \mathrm{O}_{2} \cdot{ }^{87}$ Gene expression in keratinocytes, which is induced by solar UVA radiation, is initiated at the level of the cell membrane via generation of ${ }^{1} \mathrm{O}_{2}$ and subsequent formation of ceramide from sphingomyelin. ${ }^{88}$
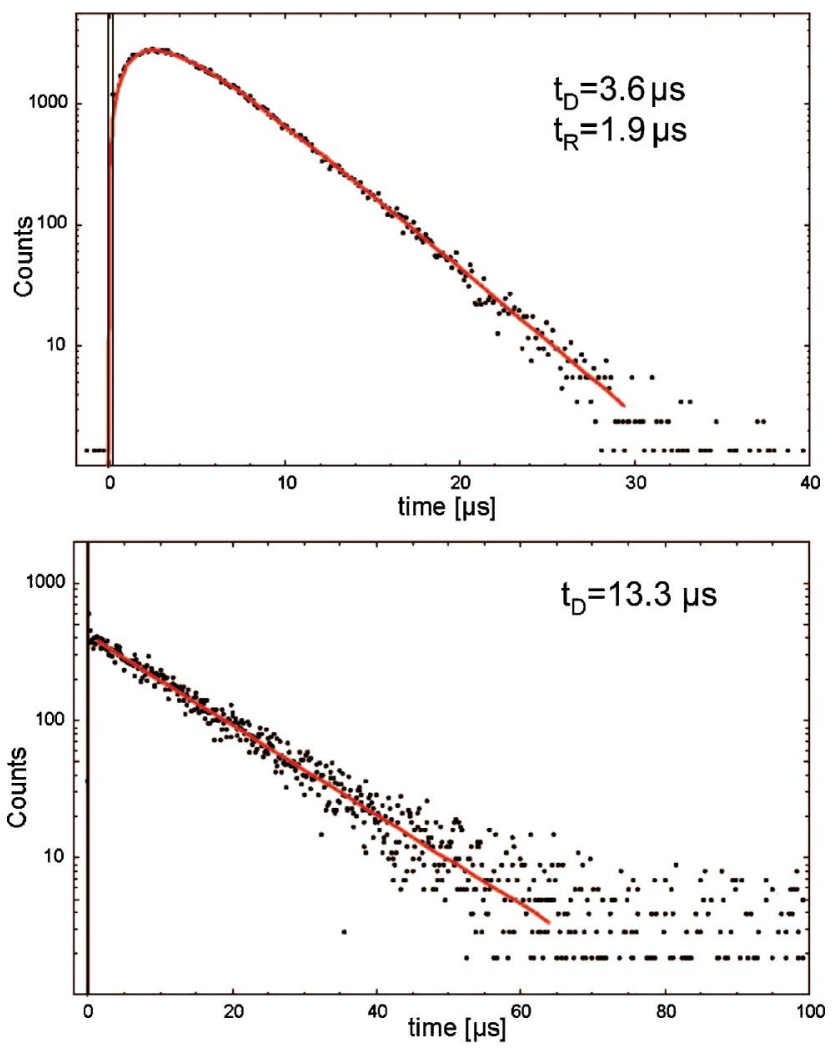

Fig. 8 The time-resolved ${ }^{1} \mathrm{O}_{2}$ luminescence signals of a porphyrin photosensitizer $(5,10,15,20$-tetrakis ( $N$-methyl-4-pyridyl)-21 $H, 23 H$-porphine, TMPyP) in water and linoleic acid in ethanol. The signal of fatty acids shows no rise time.

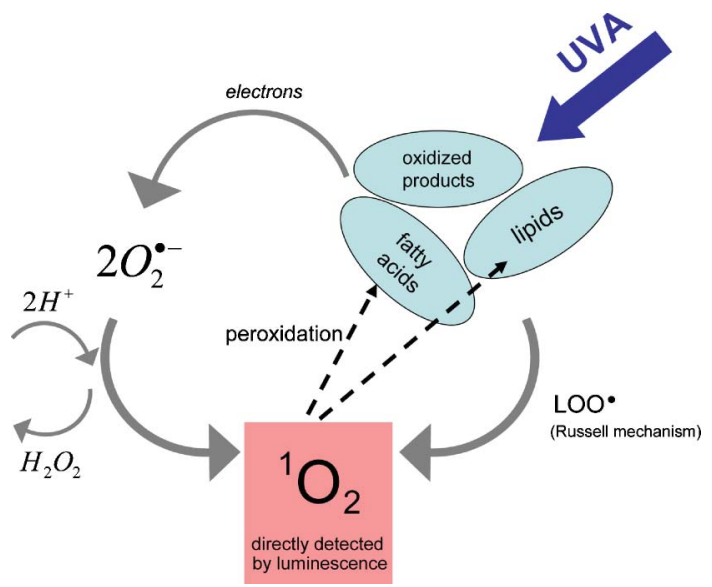

Fig. 9 Proposed scheme of UVA-initiated singlet oxygen generation with the assistance of radicals (taken from reference Baier et al. ${ }^{74}$ ).

Additionally, UVA radiation is now recognized as a class I carcinogen ${ }^{89}$ and is suspected to play a significant role in the induction of melanoma, ${ }^{90,91}$ although the latter is still a controversial issue. ${ }^{92}{ }^{1} \mathrm{O}_{2}$ is clearly induced in living skin by UVA radiation, but one has to consider that the quantum yield $\Phi_{\Delta}$ depends critically on the respective oxygen concentration, which is in skin substantially smaller as compared to aerated solutions (Fig. 11). ${ }^{15}$

In light of these facts, there is a need for a detection system that monitors the generation of ${ }^{1} \mathrm{O}_{2}$ in tissue in vivo for different 



Fig. 10 The clear and impressive time- and spectrally resolved ${ }^{1} \mathrm{O}_{2}$ luminescence signals of skin moisture.



Fig. 11 The quantum yield of ${ }^{1} \mathrm{O}_{2}$ generation for different oxygen concentrations. The vertical bar indicates the oxygen concentration in a living cell (taken from Schenkman et al. ${ }^{103}$ ).

experimental conditions. The results should be correlated to the biological findings. By means of the highly sensitive luminescence detection, we succeeded in detecting ${ }^{1} \mathrm{O}_{2}$ in living cells and even in skin in vivo, without any exogenous photosensitizer. ${ }^{36}$ At present, the luminescence technology seems to be the only method to detect ${ }^{1} \mathrm{O}_{2}$ in vivo since it is difficult or impossible to apply quencher or other reporter substances.

\section{Conclusion}

The direct detection of ${ }^{1} \mathrm{O}_{2}$ by its luminescence is a fascinating tool, which has been used in photodynamic therapy and UVAmediated photoreactions. The luminescence may report on the generation and the lifetime of ${ }^{1} \mathrm{O}_{2}$ in various environments. Due to the weak signal intensity, the luminescence detection was limited to experiments in solution at the beginning. For more than ten years, the development of new infrared sensitive photomultipliers has enabled many researchers to extend such luminescence detection to living cells in vitro and to tissue in vivo. However, there is still need to improve this technology, e.g. by looking for detectors that are even more sensitive.

- The high sensitivity of new detection technology should be used to reduce the excitation energy, which still affects the cell integrity during such experiments.

- The luminescence curve appears as a simple signal but contains a lot of information about ${ }^{1} \mathrm{O}_{2}$ dynamics, which requires a careful analysis and interpretation.

- In the case of living cells, it would be of great importance to develop a CCD camera-like detector of ${ }^{1} \mathrm{O}_{2}$ that allows the luminescence detection with spatial resolution.

- Computer-assisted modeling may help to simulate the diffusion of excitation and luminescence photons as well as the movement of ${ }^{1} \mathrm{O}_{2}$ in cells.

\section{Acknowledgements}

This study was partly supported by the Deutsche Forschungsgeneinschaft (DFG, grant BA 1741/3-2).

\section{References}

1 S. L. Parker, T. Tong, S. Bolden and P. A. Wingo, Cancer statistics, Ca-Cancer J. Clin., 1997, 47, 5-27.

2 S. Seite, A. Fourtanier, D. Moyal and A. R. Young, Photodamage to human skin by suberythemal exposure to solar ultraviolet radiation can be attenuated by sunscreens: a review, Br. J. Dermatol., 2010, 163, 903-914.

3 S. Miyamoto, G. R. Martinez, M. H. Medeiros and P. Di Mascio, Singlet molecular oxygen generated from lipid hydroperoxides by the russell mechanism: studies using 18(O)-labeled linoleic acid hydroperoxide and monomol light emission measurements, J. Am. Chem. Soc., 2003, 125, 6172-6179.

4 C. A. McCarty and H. R. Taylor, Recent developments in vision research: light damage in cataract, Invest. Ophthalmol. Vis. Sci., 1996, 37, 1720-1723.

5 D. Mitchell, Revisiting the photochemistry of solar UVA in human skin, Proc. Natl. Acad. Sci. U. S. A., 2006, 103, 13567-13568.

6 K. Wertz, P. B. Hunziker, N. Seifert, G. Riss, M. Neeb, G. Steiner, W. Hunziker and R. Goralczyk, beta-Carotene interferes with ultraviolet light A-induced gene expression by multiple pathways, J. Invest. Dermatol., 2005, 124, 428-434.

7 S. Mouret, C. Baudouin, M. Charveron, A. Favier, J. Cadet and T. Douki, Cyclobutane pyrimidine dimers are predominant DNA lesions in whole human skin exposed to UVA radiation, Proc. Natl. Acad. Sci. U. S. A., 2006, 103, 13765-13770.

8 T. Hasan, F. Nyberg, E. Stephansson, P. Puska, M. Hakkinen, S. Sarna, A. M. Ros and A. Ranki, Photosensitivity in lupus erythematosus, UV photoprovocation results compared with history of photosensitivity and clinical findings, Br. J. Dermatol., 1997, 136, 699-705.

9 P. Autier, J. F. Dore, A. M. Eggermont and J. W. Coebergh, Epidemiological evidence that UVA radiation is involved in the genesis of cutaneous melanoma, Curr. Opin. Oncol., 2011, 23, 189-196.

10 A. K. von Thaler, Y. Kamenisch and M. Berneburg, The role of ultraviolet radiation in melanomagenesis, Exp. Dermatol., 2010, 19, 81-88.

11 N. J. Neumann, A. Blotz, G. Wasinska-Kempka, M. Rosenbruch, P. Lehmann, H. J. Ahr and H. W. Vohr, Evaluation of phototoxic and photoallergic potentials of 13 compounds by different in vitro and in vivo methods, J. Photochem. Photobiol., B, 2005, 79, 25-34. 
12 J. Regensburger, K. Lehner, T. Maisch, R. Vasold, F. Santarelli, E. Engel, A. Gollmer, B. Konig, M. Landthaler and W. Baumler, Tattoo inks contain polycyclic aromatic hydrocarbons that additionally generate deleterious singlet oxygen, Exp. Dermatol., 2009, 19, e275281.

13 C. A. Morton, K. E. McKenna and L. E. Rhodes, Guidelines for topical photodynamic therapy: update, Br. J. Dermatol., 2008, 159, $1245-1266$.

14 T. Maisch, S. Hackbarth, J. Regensburger, A. Felgentrager, W. Baumler, M. Landthaler and B. Roder, Photodynamic inactivation of multi-resistant bacteria (PIB) - a new approach to treat superficial infections in the 21(st) century, J. Dtsch. Dermatol. Ges., 2011.

15 J. Baier, T. Maisch, M. Maier, E. Engel, M. Landthaler and W. Baumler, Singlet Oxygen Generation by UVA Light Exposure of Endogenous Photosensitizers, Biophys. J., 2006, 91, 1452-1459.

16 R. S. Sohal and R. Weindruch, Oxidative stress, caloric restriction, and aging, Science, 1996, 273, 59-63.

17 K. M. Hanson and J. D. Simon, Epidermal trans-urocanic acid and the UV-A-induced photoaging of the skin, Proc. Natl. Acad. Sci. U. S. A., 1998, 95, 10576-10578.

18 P. W. Albro, P. Bilski, J. T. Corbett, J. L. Schroeder and C. F. Chignell, Photochemical reactions and phototoxicity of sterols: novel self-perpetuating mechanisms for lipid photooxidation, Photochem. Photobiol., 1997, 66, 316-325.

19 Q. Xia, J. J. Yin, P. P. Fu and M. D. Boudreau, Photo-irradiation of Aloe vera by UVA-formation of free radicals, singlet oxygen, superoxide, and induction of lipid peroxidation, Toxicol. Lett., 2007, 168, 165-175.

20 C. Schweitzer and R. Schmidt, Physical mechanisms of generation and deactivation of singlet oxygen, Chem. Rev., 2003, 103, 1685-1757.

21 J. Wassell, S. Davies, W. Bardsley and M. Boulton, The photoreactivity of the retinal age pigment lipofuscin, J. Biol. Chem., 1999, 274, $23828-$ 23832.

22 A. W. Girotti and T. Kriska, Role of lipid hydroperoxides in photooxidative stress signaling, Antioxid. Redox Signaling, 2004, 6, 301-310.

23 A. Morita, T. Werfel, H. Stege, C. Ahrens, K. Karmann, M. Grewe, S. Grether-Beck, T. Ruzicka, A. Kapp, L. O. Klotz, H. Sies and J. Krutmann, Evidence that singlet oxygen-induced human $\mathrm{T}$ helper cell apoptosis is the basic mechanism of ultraviolet-A radiation phototherapy, J. Exp. Med., 1997, 186, 1763-1768.

24 M. Y. Jung and D. B. Min, ESR study of the singlet oxygen quenching and protective activity of Trolox on the photodecomposition of riboflavin and lumiflavin in aqueous buffer solutions, J. Food Sci., 2009, 74, C449-455.

25 N. Agrawal, R. S. Ray, M. Farooq, A. B. Pant and R. K. Hans, Photosensitizing potential of ciprofloxacin at ambient level of UV radiation, Photochem. Photobiol., 2007, 83, 1226-1236.

26 D. Ali, R. S. Ray and R. K. Hans, UVA-induced cyototoxicity and DNA damaging potential of benz (e) acephenanthrylene, Toxicol. Lett., 2010, 199, 193-200.

27 D. Costa, E. Fernandes, J. L. Santos, D. C. Pinto, A. M. Silva and J. L. Lima, New noncellular fluorescence microplate screening assay for scavenging activity against singlet oxygen, Anal. Bioanal. Chem., 2007, 387, 2071-2081.

28 S. Hackbarth, J. Schlothauer, A. Preuss and B. Roder, New insights to primary photodynamic effects-Singlet oxygen kinetics in living cells, J. Photochem. Photobiol., B, 2010, 98, 173-179.

29 M. T. Jarvi, M. J. Niedre, M. S. Patterson and B. C. Wilson, The influence of oxygen depletion and photosensitizer triplet-state dynamics during photodynamic therapy on accurate singlet oxygen luminescence monitoring and analysis of treatment dose response, Photochem. Photobiol., 2011, 87, 223-234.

30 A. Jimenez-Banzo, X. Ragas, S. Abbruzzetti, C. Viappiani, B. Campanini, C. Flors and S. Nonell, Singlet oxygen photosensitisation by GFP mutants: oxygen accessibility to the chromophore, Photochem. Photobiol. Sci., 2010, 9, 1336-1341.

31 P. R. Ogilby, Singlet oxygen: there is still something new under the sun, and it is better than ever, Photochem. Photobiol. Sci., 2010, 9, $1543-1560$.

32 J. Baier, M. Maier, R. Engl, M. Landthaler and W. Baumler, Timeresolved investigations of singlet oxygen luminescence in water, in phosphatidylcholine, and in Aqueous suspensions of phosphatidylcholine or HT29 cells, J. Phys. Chem. B, 2005, 109, 3041-3046.

33 J. Regensburger, T. Maisch, A. Felgentrager, F. Santarelli and W. Baumler, A helpful technology-the luminescence detection of singlet oxygen to investigate photodynamic inactivation of bacteria (PDIB), J. Biophotonics, 2010, 3, 319-327.

34 S. Miyamoto, G. R. Martinez, A. P. Martins, M. H. Medeiros and P. Di Mascio, Direct evidence of singlet molecular oxygen [O2(1Deltag)] production in the reaction of linoleic acid hydroperoxide with peroxynitrite, J. Am. Chem. Soc., 2003, 125, 4510-4517.

35 J. R. Kanofsky, Measurement of singlet-oxygen in vivo: progress and pitfalls, Photochem. Photobiol., 2011, 87, 14-17.

36 J. Baier, T. Maisch, M. Maier, M. Landthaler and W. Baumler, Direct Detection of Singlet Oxygen Generated by UVA Irradiation in Human Cells and Skin, J. Invest. Dermatol., 2007, 127, 1498-1506.

37 A. Baker and J. R. Kanofsky, Quenching of singlet oxygen by biomolecules from L1210 leukemia cells, Photochem. Photobiol., 1992, 55, 523-528.

38 M. K. Kuimova, G. Yahioglu and P. R. Ogilby, Singlet oxygen in a cell: spatially dependent lifetimes and quenching rate constants, $J$. Am. Chem. Soc., 2009, 131, 332-340.

39 M. J. Niedre, M. S. Patterson, A. Giles and B. C. Wilson, Imaging of photodynamically generated singlet oxygen luminescence in vivo, Photochem. Photobiol., 2005, 81, 941-943.

40 A. Jimenez-Banzo, X. Ragas, P. Kapusta and S. Nonell, Time-resolved methods in biophysics. 7. Photon counting vs. analog time-resolved singlet oxygen phosphorescence detection, Photochem. Photobiol. Sci., 2008, 7, 1003-1010.

41 M. Niedre, M. S. Patterson and B. C. Wilson, Direct near-infrared luminescence detection of singlet oxygen generated by photodynamic therapy in cells in vitro and tissues in vivo, Photochem. Photobiol., 2002, 75, 382-391.

42 J. Baier, T. Fuß, C. Pöllmann, C. Wiesmann, K. Pindl, R. Engl, D. Baumer, M. Maier, M. Landthaler and W. Bäumler, Theoretical and experimental analysis of the luminescence signal of singlet oxygen for different photosensitizers, J. Photochem. Photobiol., B, 2007, 87, $163-173$.

43 D. Baumer, M. Maier, R. Engl, R. M. Szeimies and W. Baumler, Singlet oxygen generation by 9 -acetoxy-2,7,12,17-tetrakis-(Betamethoxyethyl)-porphycene (ATMPn) in solution, Chem. Phys., 2002, 285, 309-318.

44 T. Maisch, J. Baier, B. Franz, M. Maier, M. Landthaler, R. M. Szeimies and W. Bäumler, The role of singlet oxygen and oxygen concentration in photodynamic inactivation of bacteria, Proc. Natl. Acad. Sci. U.S. A., 2007, 104, 7223-7228.

45 F. Wilkinson, W. P. Helman and A. B. Ross, Rate constants for the decay and reactions of the lowest electronically excited singlet state of molecular oxygen in solution. An expanded and revised compilation, J. Phys. Chem. Ref. Data, 1995, 24, 663-1021.

46 J. Cadet, T. Douki, J. L. Ravanat and P. Di Mascio, Sensitized formation of oxidatively generated damage to cellular DNA by UVA radiation, Photochem. Photobiol. Sci., 2009, 8, 903-911.

47 M. Dalle Carbonare and M. A. Pathak, Skin photosensitizing agents and the role of reactive oxygen species in photoaging, J. Photochem. Photobiol., B, 1992, 14, 105-124.

48 R. M. Tyrrell, Solar ultraviolet A radiation: an oxidizing skin carcinogen that activates heme oxygenase-1, Antioxid. Redox Signal., 2004, 6, 835-840.

49 L. B. Avalle, J. Dillon, S. Tari and E. R. Gaillard, A new approach to measuring the action spectrum for singlet oxygen production by human retinal lipofuscin, Photochem. Photobiol., 2005, 81, 13471350.

50 R. E. Musson, P. J. Hensbergen, A. H. Westphal, W. P. Temmink, A. M. Deelder, J. van Pelt, L. H. Mullenders and N. P. Smit, UVA1 radiation inhibits calcineurin through oxidative damage mediated by photosensitization, Free Radical Biol. Med., 2011.

51 S. D. Lamore, S. Azimian, D. Horn, B. L. Anglin, K. Uchida, C. M. Cabello and G. T. Wondrak, The malondialdehyde-derived fluorophore DHP-lysine is a potent sensitizer of UVA-induced photooxidative stress in human skin cells, J. Photochem. Photobiol., $B, 2010,101,251-264$.

52 Y. Zhang, X. Zhu, J. Smith, M. T. Haygood and R. Gao, Direct observation and quantitative characterization of singlet oxygen in aqueous solution upon UVA excitation of 6-thioguanines, J. Phys. Chem. B, 2011, 115, 1889-1894.

53 A. H. Thomas, C. Lorente, A. L. Capparelli, C. G. Martinez, A. M. Braun and E. Oliveros, Singlet oxygen (1deltag) production by pterin derivatives in aqueous solutions, Photochem. Photobiol. Sci., 2003, 2, $245-250$. 
54 J. J. Yin, Q. Xia and P. P. Fu, UVA photoirradiation of anhydroretinolformation of singlet oxygen and superoxide, Toxicol. Ind. Health, 2007, 23, 625-631.

55 X. Ragas, L. P. Cooper, J. H. White, S. Nonell and C. Flors, Quantification of photosensitized singlet oxygen production by a fluorescent protein, ChemPhysChem, 2011, 12, 161-165.

56 S. Jantova, K. Konarikova, S. Letasiova, E. Paulovicova, V. Milata and V. Brezova, Photochemical and phototoxic properties of ethyl 1,4-dihydro-8-nitro-4-oxoquinoline-3-carboxylate, a new quinoline derivative, J. Photochem. Photobiol., B, 2011, 102, 77-91.

57 R. S. Ray, N. Agrawal, R. B. Misra, M. Farooq and R. K. Hans, Radiation-induced in vitro phototoxic potential of some fluoroquinolones, Drug Chem. Toxicol., 2006, 29, 25-38.

58 Z. Barbierikova, M. Bella, J. Kucerak, V. Milata, S. Jantova, D. Dvoranova, M. Vesela, A. Stasko and V. Brezova, Photoinduced superoxide radical anion and singlet oxygen generation in the presence of novel selenadiazoloquinolones (an EPR Study), Photochem. Photobiol., 2011, 87, 32-44.

59 B. Quintero and M. A. Miranda, Mechanisms of photosensitization induced by drugs: A general survey, Ars Pharmaceutica, 2000, 41, 27-46.

60 L. J. Martinez and J. C. Scaiano, Characterization of the transient intermediates generated from the photoexcitation of nabumetone: a comparison with naproxen, Photochem. Photobiol., 1998, 68, 646-651.

61 F. Vargas, K. Carbonell and M. Camacho, Photochemistry and in vitro phototoxicity studies of levomepromazine (methotrimeprazine), a phototoxic neuroleptic drug, Pharmazie, 2003, 58, 315-319.

62 P. J. Bilski, M. A. Wolak, V. Zhang, D. E. Moore and C. F. Chignell, Photochemical reactions involved in the phototoxicity of the anticonvulsant and antidepressant drug lamotrigine (Lamictal), Photochem. Photobiol., 2009, 85, 1327-1335.

63 A. Wolnicka-Glubisz, M. Lukasik, A. Pawlak, A. Wielgus, M. Niziolek-Kierecka and T. Sarna, Peroxidation of lipids in liposomal membranes of different composition photosensitized by chlorpromazine, Photochem. Photobiol. Sci., 2009, 8, 241-247.

64 S. Onoue, N. Igarashi, Y. Yamauchi, T. Kojima, N. Murase, Y. Zhou, S. Yamada and Y. Tsuda, In vitro phototoxic potential and photochemical properties of imidazopyridine derivative: a novel 5HT4 partial agonist, J. Pharm. Sci., 2008, 97, 4307-4318.

65 S. Onoue, N. Igarashi, Y. Yamauchi, N. Murase, Y. Zhou, T. Kojima, S. Yamada and Y. Tsuda, In vitro phototoxicity of dihydropyridine derivatives: a photochemical and photobiological study, Eur. J. Pharm. Sci., 2008, 33, 262-270.

66 J. Kolosnjaj, H. Szwarc and F. Moussa, Toxicity studies of fullerenes and derivatives, Adv. Exp. Med. Biol., 2007, 620, 168-180.

67 B. Zhao, Y. Y. He, C. F. Chignell, J. J. Yin, U. Andley and J. E. Roberts, Difference in phototoxicity of cyclodextrin complexed fullerene [(gamma-CyD)2/C60] and its aggregated derivatives toward human lens epithelial cells, Chem. Res. Toxicol., 2009, 22, 660-667.

68 L. Bao, A. Xu, L. Tong, S. Chen, L. Zhu, Y. Zhao, G. Zhao, E. Jiang, J. Wang and $\mathrm{L}$. Wu, Activated toxicity of diesel particulate extract by ultraviolet a radiation in mammalian cells: role of singlet oxygen, Environ. Health Perspect., 2009, 117, 436-441.

69 M. J. Llansola Portoles, P. M. Gara, M. L. Kotler, S. Bertolotti, E. San Roman, H. B. Rodriguez and M. C. Gonzalez, Silicon nanoparticle photophysics and singlet oxygen generation, Langmuir, 2010, 26, 10953-10960.

70 N. Krinsky, Singlet oxygen in biological systems, Trends Biochem. Sci., 1977, 2, 35-38.

71 J. Cadet, J. L. Ravanat, G. R. Martinez, M. H. Medeiros and P. Di Mascio, Singlet oxygen oxidation of isolated and cellular DNA: product formation and mechanistic insights, Photochem. Photobiol., 2006, 82, 1219-1225.

72 A. W. Girotti, Lipid hydroperoxide generation, turnover, and effector action in biological systems, J. Lipid Res., 1998, 39, 1529-1542.

73 R. L. Arudi, M. W. Sutherland and B. H. Bielski, Purification of oleic acid and linoleic acid, J. Lipid Res., 1983, 24, 485-488.

74 J. Baier, T. Maisch, J. Regensburger, C. Pollmann and W. Baumler, Optical detection of singlet oxygen produced by fatty acids and phospholipids under ultraviolet A irradiation, J. Biomed. Opt., 2008, 13, 044029 .

75 H. W. Gardner, Oxygen radical chemistry of polyunsaturated fatty acids, Free Radical Biol. Med., 1989, 7, 65-86.

76 S. Miyamoto, G. E. Ronsein, F. M. Prado, M. Uemi, T. C. Correa, I. N. Toma, A. Bertolucci, M. C. Oliveira, F. D. Motta, M. H. Medeiros and P. D. Mascio, Biological hydroperoxides and singlet molecular oxygen generation, IUBMB Life, 2007, 59, 322-331.

77 G. A. Russell, Deuterium isotope effects in the autooxidation of aralkyl hydrocarbons. Mechanisms of the interaction of peroxy radicals, J. Am. Chem. Soc., 1957, 79, 3871-3877.

78 D. G. Mendenhall, C. Sheng and T. Wilson, Yields of excited carbonyl species from alkoxyl and from alkylperoxyl radical dismutations, $J$. Am. Chem. Soc., 1991, 113, 8976-8977.

79 H. Baumgärtl, A. Ehrly, K. Saeger-Lorenz, D. Lübbers, J. H. A. M. Ehrly and S. R. Huch, Initial results of intracutaneous measurements of pO2 profiles, in Clinical oxygen pressure measurement, ed. A. M. Ehrly, J. Hauss and R. Huch, Springer, Berlin, Heidelberg, New York, 1987, Berlin, Germany, pp. 121-128.

80 N. Bando, H. Hayashi, S. Wakamatsu, T. Inakuma, M. Miyoshi, A. Nagao, R. Yamauchi and J. Terao, Participation of singlet oxygen in ultraviolet-a-induced lipid peroxidation in mouse skin and its inhibition by dietary beta-carotene: an ex vivo study, Free Radical Biol. Med., 2004, 37, 1854-1863.

81 G. F. Vile and R. M. Tyrrell, UVA radiation-induced oxidative damage to lipids and proteins in vitro and in human skin fibroblasts is dependent on iron and singlet oxygen, Free Radical Biol. Med., 1995, 18, 721-730.

82 S. Grether-Beck, G. Bonizzi, H. Schmitt-Brenden, I. Felsner, A. Timmer, H. Sies, J. P. Johnson, J. Piette and J. Krutmann, Nonenzymatic triggering of the ceramide signalling cascade by solar UVA radiation, EMBO J., 2000, 19, 5793-5800.

83 M. A. Lampe, A. L. Burlingame, J. Whitney, M. L. Williams, B. E. Brown, E. Roitman and P. M. Elias, Human stratum corneum lipids: characterization and regional variations, J. Lipid Res., 1983, 24, 120130.

84 B. Catalgol, I. Ziaja, N. Breusing, T. Jung, A. Hohn, B. Alpertunga, P. Schroeder, N. Chondrogianni, E. S. Gonos, I. Petropoulos, B. Friguet, L. O. Klotz, J. Krutmann and T. Grune, The proteasome is an integral part of solar ultraviolet a radiation-induced gene expression, J. Biol. Chem., 2009, 284, 30076-30086.

85 Y. Minami, K. Yokoyama, N. Bando, Y. Kawai and J. Terao, Occurrence of singlet oxygen oxygenation of oleic acid and linoleic acid in the skin of live mice, Free Radical Res., 2008, 42, 197-204.

86 C. S. Sander, H. Chang, S. Salzmann, C. S. Muller, S. EkanayakeMudiyanselage, P. Elsner and J. J. Thiele, Photoaging is associated with protein oxidation in human skin in vivo, J. Invest. Dermatol., $2002,118,618-625$.

87 Y. Minami, K. Kawabata, Y. Kubo, S. Arase, K. Hirasaka, T. Nikawa, N. Bando, Y. Kawai and J. Terao, Peroxidized cholesterol-induced matrix metalloproteinase-9 activation and its suppression by dietary beta-carotene in photoaging of hairless mouse skin, J. Nutr. Biochem., 2009, 20, 389-398.

88 S. Grether-Beck, M. Salahshour-Fard, A. Timmer, H. Brenden, I. Felsner, R. Walli, J. Fullekrug and J. Krutmann, Ceramide and raft signaling are linked with each other in UVA radiation-induced gene expression, Oncogene, 2008, 27, 4768-4778.

89 F. El Ghissassi, R. Baan, K. Straif, Y. Grosse, B. Secretan, V. Bouvard, L. Benbrahim-Tallaa, N. Guha, C. Freeman, L. Galichet and V. Cogliano, A review of human carcinogens-part D: radiation, Lancet Oncol., 2009, 10, 751-752.

90 A. K. von Thaler, Y. Kamenisch and M. Berneburg, The role of ultraviolet radiation in melanomagenesis, Exp. Dermatol., 2010, 19, 81-88.

91 E. Kvam and R. M. Tyrrell, Induction of oxidative DNA base damage in human skin cells by UV and near visible radiation, Carcinogenesis, 1997, 18, 2379-2384.

92 M. R. Zaidi, S. Davis, F. P. Noonan, C. Graff-Cherry, T. S. Hawley, R. L. Walker, L. Feigenbaum, E. Fuchs, L. Lyakh, H. A. Young, T. J. Hornyak, H. Arnheiter, G. Trinchieri, P. S. Meltzer, E. C. De Fabo and G. Merlino, Interferon-gamma links ultraviolet radiation to melanomagenesis in mice, Nature, 2011, 469, 548-553.

93 A. A. Krasnovsky Jr. and V. E. Kagan, Photosensitization and quenching of singlet oxygen by pigments and lipids of photoreceptor cells of the retina, FEBS Lett., 1979, 108, 152-154.

94 C. M. Krishna, S. Uppuluri, P. Riesz, J. S. Zigler Jr. and D. Balasubramanian, A study of the photodynamic efficiencies of some eye lens constituents, Photochem. Photobiol., 1991, 54, 5158.

95 B. M. Dzhagarov, N. N. Kruk, N. V. Konovalova, A. A. Solodunov and I. I. Stepuro, Quantum yield of photosensitized formation of 
singet oxygen by vitamines of the B6 group and their adducts with amino acids and proteins, J. Appl. Spectrosc., 1995, 62, 122127.

96 E. Oliveros, F. Besançon, M. Boneva, B. Kräutler and A. Braun, Singlet oxygen $(1 \Delta \mathrm{g})$ sensitization and quenching by vitamin $\mathrm{B} 12$ derivatives, J. Photochem. Photobiol., B, 1995, 29, 37-44.

97 S. Dad, R. H. Bisby, I. P. Clark and A. W. Parker, Formation of singlet oxygen from solutions of vitamin E, Free Radical Res., 2006, 40, 333-338.

98 A. A. Gorman, I. Hamblett and M. A. Rodgers, Ergosterol (provitamin D2) triplet state: an efficient sensitiser of singlet oxygen, O2(1 delta g), formation, Photochem. Photobiol., 1987, 45, 215221.

99 M. Rozanowska, J. Wessels, M. Boulton, J. M. Burke, M. A. Rodgers, T. G. Truscott and T. Sarna, Blue light-induced singlet oxygen generation by retinal lipofuscin in non-polar media, Free Radical Biol. Med., 1998, 24, 1107-1112.

100 L. J. Martinez, R. H. Sik and C. F. Chignell, Fluoroquinolone antimicrobials: singlet oxygen, superoxide and phototoxicity, Photochem. Photobiol., 1998, 67, 399-403.

101 T. Arai, Y. Nishimura, M. Sasaki, H. Fujita, I. Matsuo, H. Sakuragi and K. Tokumaru, Mechanism of production of singlet oxygen on photoexcitation of drugs inducing photosensitivity, Bull. Chem. Soc. Jpn., 1991, 64, 2169-2173.

102 B. Ehrenberg, J. L. Anderson and C. S. Foote, Kinetics and yield of singlet oxygen photosensitized by hypericin in organic and biological media, Photochem. Photobiol., 1998, 68, 135-140.

$103 \mathrm{~K}$. A. Schenkman, Cardiac performance as a function of intracellular oxygen tension in buffer-perfused hearts, Am. J. Physiol. Heart Circ. Physiol., 2001, 281, H2463-2472. 